\title{
Analysis of deep-layer and bottom circulations in the South China Sea based on eight quasi-global ocean model outputs
}

\author{
XIE Qiang ${ }^{1,3}$, XIAO JinGen ${ }^{1,2}$, WANG DongXiao ${ }^{1 *} \&$ YU YongQiang ${ }^{4}$ \\ ${ }^{1}$ State Key Laboratory of Tropical Oceanography, South China Sea Institute of Oceanology, Chinese Academy of Sciences, \\ Guangzhou 510301, China; \\ ${ }^{2}$ University of the Chinese Academy of Sciences, Beijing 100049, China; \\ ${ }^{3}$ Sanya Institute of Deep Sea Science and Engineering, Chinese Academy of Sciences, Sanya 572000, China, \\ ${ }^{4}$ State Key Laboratory of Atmospheric Sciences and Geophysical Fluid Dynamics, Institute of Atmospheric Physics, \\ Chinese Academy of Sciences, Beijing 100029, China
}

Received November 14, 2012; accepted February 22, 2013; published online June 24, 2013

\begin{abstract}
This study is a preliminary analysis of the South China Sea (SCS) deep circulations using eight quasi-global high-resolution ocean model outputs. The goal is to assess models' ability to simulate these deep circulations. The analysis reveals that models' deep temperatures are colder than the observations in the World Ocean Atlas, while most models' deep salinity values are higher than the observations, indicating models' deep water is generally colder and saltier than the reality. Moreover, there are long-term trends in both temperature and salinity simulations. The Luzon Strait transport below $1500 \mathrm{~m}$ is $0.36 \mathrm{~Sv}$ when averaged for all models, smaller compared with the observation, which is about $2.5 \mathrm{~Sv}$. Four assimilated models and one unassimilated (OCCAM) display that the Luzon deep-layer overflow reaches its minimum in spring and its maximum in winter. The vertically integrated streamfunctions below $2400 \mathrm{~m}$ from these models show a deep cyclonic circulation in the SCS on a large scale, but the pattern is different from the diagnostic streamfunction from the U.S Navy Generalized Digital Environment Model (GDEM-Version 3.0, GDEMv3). The meridional overturning structure above $1000 \mathrm{~m}$ is similar in all models, but the spatial distribution and intensity below $1500 \mathrm{~m}$ are quite different from model to model. Moreover, the meridional overturning below $2400 \mathrm{~m}$ in these models is weaker than that of the GDEMv3, which indicates a deep vertical mixing process in these models is biased weak. Based on the above evaluation, this paper discusses the impacts of T/S initial value, topography, and mixing scheme on the SCS deep circulations, which may provide a reference for future model improvement.
\end{abstract}

quasi-global ocean model, deep-layer and bottom SCS circulations, model evaluation

Citation: Xie Q, Xiao J G, Wang D X, et al. Analysis of deep-layer and bottom circulations in the South China Sea based on eight quasi-global ocean model outputs. Chin Sci Bull, 2013, 58: 4000-4011, doi: 10.1007/s11434-013-5791-5

Assuming there be one deep-water formation site at each pole with uniform upwelling elsewhere globally and flat bottom for each ocean basin, the classical abyssal circulation theory predicts that the weak interior flow should be poleward with strong western boundary currents equatorward in the deep ocean [1,2]. The existence of the deep western boundary current in the North Atlantic confirms this theory. As for the South China Sea (SCS) in the tropical region, there is no deep-water formation site. Moreover,

*Corresponding author (email: dxwang@scsio.ac.cn) there is only the Luzon Strait that connects the SCS below $2000 \mathrm{~m}$. So the intruding Pacific Deep Water is the original water mass for the deep SCS. The existing observations show that the properties of the deep water mass in the SCS are similar to those in the deep western Philippine Sea $[3,4]$, which supports that notion that the deep SCS water mass comes from the Pacific Deep Water via the Luzon Strait [5]. Since the Pacific Deep Water is colder and of higher density, it sinks after crossing the Luzon Strait. To compensate for this descending movement, upwelling must occur elsewhere in the SCS, and thus the renewal of the SCS deep water is 
rapid compared with its Pacific counterpart. So, the Luzon Strait deep overflow forces the SCS deep circulation. Based on hydrological data, the transport of the Luzon Strait deep overflow is from 1 to $3 \mathrm{~Sv}$ [6-16]. Moreover, reflection seismic profiles show that drift sediments occur in the depth range of 1200-2800 $\mathrm{m}$ on the continental margin off Southeast China. These drift deposits were generated by upward flow near the Dongsha Islands of the North Pacific Deep Water (NPDW), which enters the SCS via the Bashi Channel [17-19].

Only Chao et al. [20] and Yuan [21] have shown ocean model outputs of the SCS deep circulation. Using a $0.4^{\circ} \times 0.4^{\circ}$ free-surface ocean model with climatoligical wind focing and observed strait fluxes, Chao et al. [20] identified two primary regions of deep upwelling responsible for deep water renewal: southwest of Taiwan and off Vietnam coast. And the time of deep-water renewal is about 83 years. There is a deep western boundary current that is equatorward, with a weak eastern boundary current that also flows equatorward. Based on $0.16^{\circ} \times 0.16^{\circ} \mathrm{MOM} 2$ driven by specified Philippine Sea currents and no wind stresses (in addition, all other channels between the SCS and Indonesian seas are closed so that the focus is on the Luzon Stait transport), Yuan [21] showed that the simulated Luzon Strait transport and the SCS circulation feature a sandwiched vertical structure from surface to bottom. The Philippine Sea water enters the SCS at the surface and in the deep ocean, and is carried to the southern basin by western boundary currents. At intermediate depth, the net Luzon Strait transport is out of the SCS into the Pacific, and is fed by a western boundary current flowing to the north at the base of thermocline. Corresponding to the western boundary current, the basin circulation of the SCS is cyclonic both at the surface and in the abyss but anti-cyclonic at the intermediate depth.

There are many high-resolution ocean model outputs that can be downloaded freely, such as OFES [22], HYCOM [23], JPL-R [24], BRAN [25], and LICOM [26]. These model outputs can be used to assess the ocean models' ability of reproducing the deep SCS circulation; for example, when the Luzon deep overflow and meridional overturning circulation in the models are analyzed. Then, we may find model deficiency and provide suggestions for model improvement.

\section{Data and method}

Detailed information of eight model outputs used in this study is listed in Table 1. We use SODA as a reference for other model outputs, including the other three dataassimilated outputs. Since the atmospheric forcing and initial T/S fields are different in each model, we can use such differences to study sensitivities of deep SCS circulations to external forcing. The horizontal resolution is about $0.16^{\circ}$, and the vertical resolution is from 200 to $500 \mathrm{~m}$ below 2000 $\mathrm{m}$. Although the vertical resolution is not high, the deep water mass is nearly uniform, so these outputs are adequate for analyzing the property of deep SCS circulation. In addition, two climatological T/S datasets of WOA01 [27] and GDEMv3[28](http://www.usgodae.org/pub/outgoing/static/ ocn/gdem/) are used.

The methods used for analysis are defined next.

\subsection{Transport across a strait}

$$
F_{v}=\int_{A} v_{n} \mathrm{~d} A,
$$

where $A$ denotes strait width, and $v_{n}$ is the velocity perpendicular to the strait.

\subsection{Horizontal streamfunction}

Since the horizontal velocity is larger than vertical velocity by nearly 3-4 orders in the ocean, the flow field can be regarded as nondivergent. Then, there is a streamfunction derived from horizontal velocities. The function can be defined as

$$
\int_{(1,1)}^{(i, j)} d \psi=\int_{(1,1)}^{(i, j)}(-v \mathrm{~d} x+u \mathrm{~d} y) .
$$

Because $\psi(1,1)$ is located at the boundary, its value can be set to 0 . It is found that the integration from the eastern

\begin{tabular}{|c|c|c|c|c|c|c|c|c|}
\hline Dataset & SODA & $\mathrm{ECCO} 2$ & HYCOM & BRAN & OCCAM & JPL-R & LICOM & OFES \\
\hline Ocean model & POP & MITgcm & hycom & MOM4.0 & GFDL $\mathrm{gcm}$ & ROMS & LICOM2.0 & MOM3 \\
\hline Grid & $0.4^{\circ} \times 0.25^{\circ}$ & $0.25^{\circ}$ & $\sim 0.08^{\circ}$ & $\sim 0.15$ & $0.08^{\circ}$ & $\sim 0.125^{\circ}$ & $0.1^{\circ}$ & $0.1^{\circ}$ \\
\hline Vertical level & 40 & 40 & 33 & 47 & 66 & 30 & 55 & 54 \\
\hline Vertical mixing & KPP & KPP & KPP & KPP & PP & KPP & Canuto $[29,30]$ & KPP \\
\hline Assimilation & yes & yes & yes & yes & no & no & no & no \\
\hline Forcing & ERA-40 & NCEP/NCAR & NOGAPS & ERA-40 & NCEP/NCAR & NCEP/NCAR & NCEP/NCAR & NCEP/NCAR \\
\hline Initial value & WOA1994 & WOA1998 & GDEMv3 & WOA2001 & WOA1998 & WOA2001 & WOA1998 & WOA1998 \\
\hline Spin-up time (a) & 0 & 10 & 10 & 12 & 12 & 60 & 10 & 50 \\
\hline Data length & 1986-2008 & 1992-2008 & 2003-2009 & 1993-2006 & 1988-2004 & 2001-2009 & 2000-2007 & $41-50$ \\
\hline
\end{tabular}

Table 1 Information on the datasets used in this study 
boundary is more accurate than from other boundaries.

\subsection{Meridional overturning steamfunction}

The meridional overturning streamfunction is defined as

$$
\psi(y, z)=\int_{x_{\mathrm{w}}}^{x_{\mathrm{e}}} \mathrm{d} x \int_{-H}^{z} v \mathrm{~d} z,
$$

where $x_{\mathrm{w}}$ and $x_{\mathrm{e}}$ denote the western and eastern boundaries, while $H$ is the depth of the ocean bottom.

\section{Results}

\subsection{Analysis of SCS deep water mass}

Figure 1 shows that the temperature bias is negative in all the models, namely, the simulated water mass is generally colder than that of World Ocean Atlas (2001, WOA01). The temperature bias in JPL-R is the largest, between $-0.33^{\circ} \mathrm{C}$ and $-0.29^{\circ} \mathrm{C}$, while that in LICOM is the smallest, between $-0.15^{\circ} \mathrm{C}$ and $-0.05^{\circ} \mathrm{C}$. The temperature biases of all the other models are between $-0.25^{\circ} \mathrm{C}$ and $-0.20^{\circ} \mathrm{C}$. However, the salinity biases at $2800 \mathrm{~m}$ are about $0.01 \mathrm{psu}$, but their values are both positive and negative (Figure 2). Figure 3(a) and (b) shows the basin-averaged biases of temperature and salinity. The temperature bias in the whole depth range is negative. Specifically, it is about $-0.3^{\circ} \mathrm{C}$ from 1500 to 2800 $\mathrm{m}$. The bias becomes larger below $2800 \mathrm{~m}$ and reaches nearly $-0.5^{\circ} \mathrm{C}$ at the bottom. As for salinity bias, the salinity bias is positive from $2000 \mathrm{~m}$ to the bottom, except for LICOM and OCCAM. In general, the simulated water mass in deep SCS is colder and saltier than that in WOA01. It may suggest that the colder and saltier intruding Pacific Deep Water from the west of the Phillipine Sea has more influence on the SCS (Figure 3(c) and (d). Since the forcing and physical processes are different in the unassimilated models, the way of reaching to the quasi-equilibrium state also varies from model to model. As shown in Figure 4, most of the models have not reached the quasi-equilibrium state. Except for BRAN, the simulated T/S values all have obvious trends, even the ones with data assimilation. The trends in SODA, OFES and HYCOM are similar, which show that the model water mass becomes colder and saltier in time. But there are opposite trends in temperature and salinity in ECCO2, JPL-R, LICOM, and OCCAM.
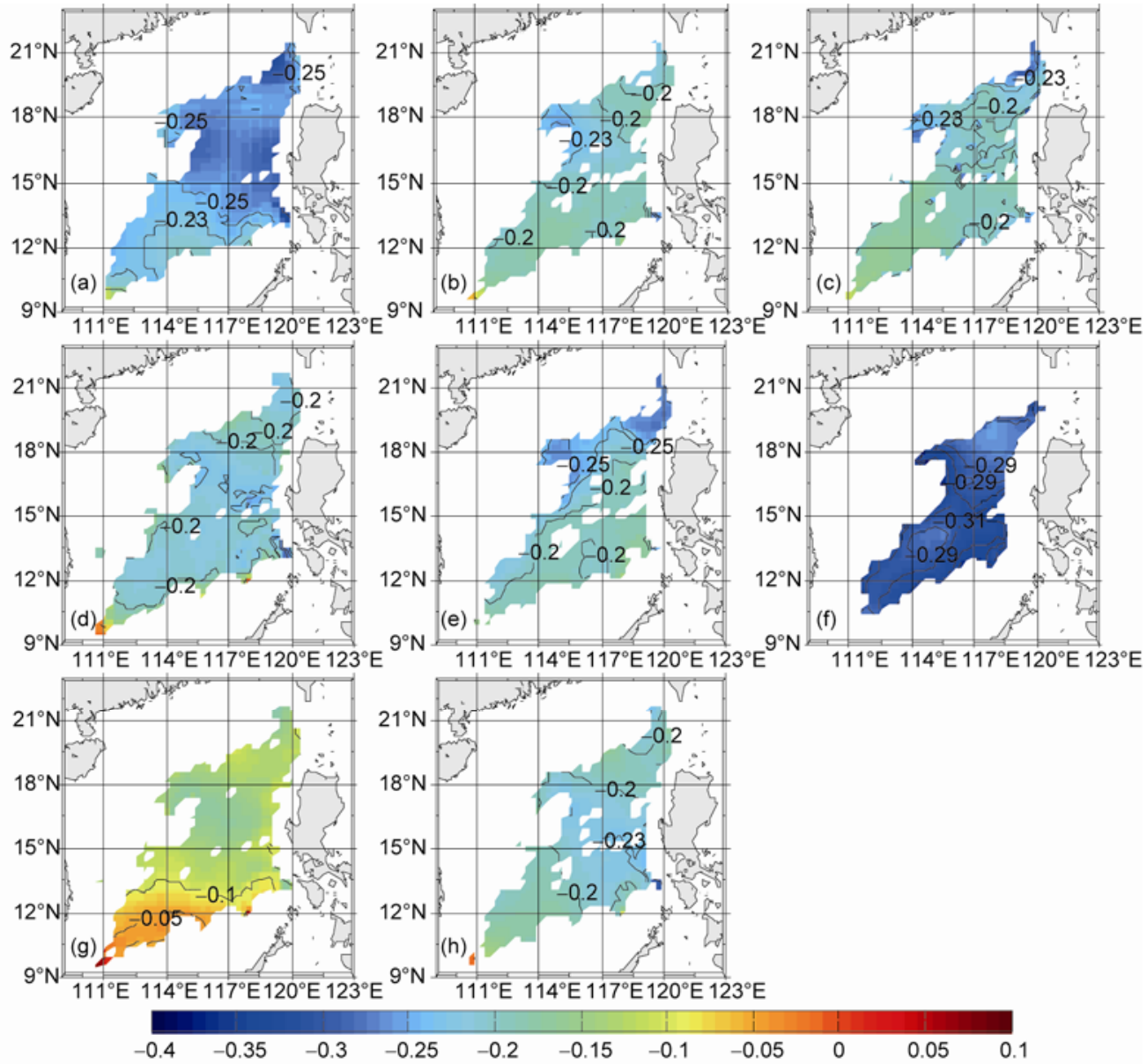

Figure 1 Temperature bias $\left({ }^{\circ} \mathrm{C}\right.$, contours and shadings) at 2800 m. (a) SODA; (b)ECCO2; (c) HYCOM; (d) BRAN; (e) OCCAM; (f) JPL-R; (g) LICOM; (h) OFES. 


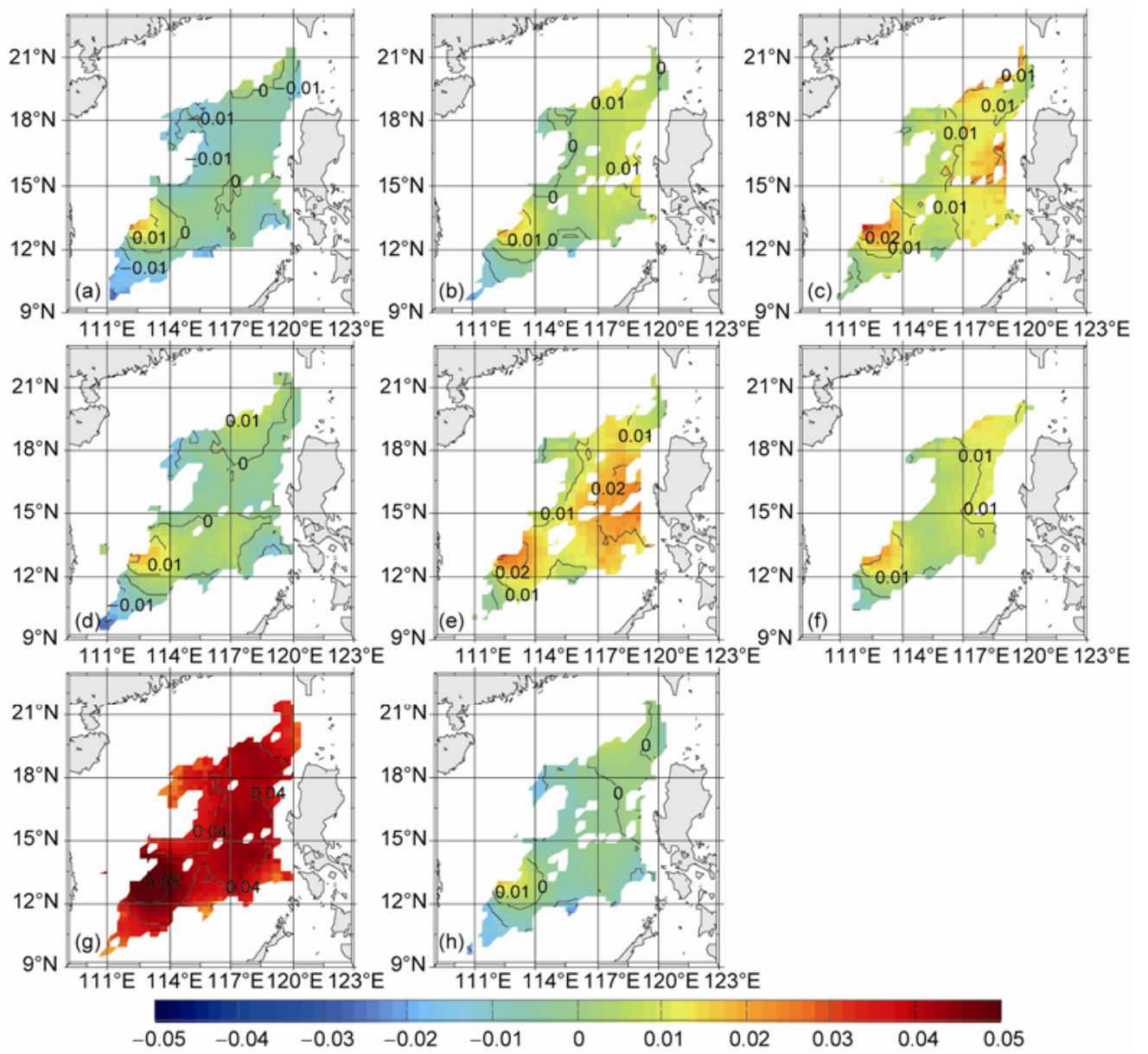

Figure 2 Salinity bias (psu, contours and shadings) at 2800 m. (a) SODA; (b) ECCO2; (c) HYCOM; (d) BRAN; (e) OCCAM; (f) JPL-R; (g) LICOM; (h) OFES.

\subsection{Luzon Strait deep overflow}

Qu et al. [10] estimated the Luzon Strait deep overflow is nearly $2.5 \mathrm{~Sv}$. Some other results of this study include (1) a residence time of less than 30 years in the deep SCS, (2) a mean diapycnal diffusivity as large as $10^{-3} \mathrm{~m}^{2} \mathrm{~s}^{-1}$, and (3) an abyssal upwelling rate of about $3 \times 10^{-6} \mathrm{~ms}^{-1}$. Tian et al. [12] confirmed that the Luzon Strait transport has a sandwiched vertical structure. The net westward volume transport (into the SCS) in the deep (>1500 m) layer of the Luzon Strait reaches 2 Sv. Yang et al. [14] found that the flow pattern in the deep layer varies little from October 2005 to July 2007. As shown in Table 2, estimates of the net Luzon Strait transport are consistent with previous studies [16]. The transport of Luzon deep overflow is about $0.5 \mathrm{~Sv}$ except for JPL-R, obviously weaker compared with estimates of Tian et al. [12] and Yang et al. [14]. The multi-model mean of the Luzon Strait deep overflow is $0.36 \mathrm{~Sv}$, and the corresponding multi-model mean of standard deviation is $0.22 \mathrm{~Sv}$. The seasonal variability of Luzon Strait deep overflow in each model is as large as the mean transport itself (Figure 5), even for the assimilated outputs. The Luzon Strait deep overflow is maximum in winter and minimal in spring. The unassimilated OCCAM and all four assimilated datasets show that the net transport of Luzon Strait deep overflow is westward in July and October, which is consistent with the results of Tian et al. [12] and Yang et al. [14]. From the above analysis, we conclude that these models' ability to simulate the Luzon Strait deep overflow needs improvement.

\subsection{SCS Meridional Ocean Circulation (MOC)}

Wang et al. [31] simulated the upper SCS MOC using the GFDL general circulation model under the conditions of open or closed boundary conditions regarding the transport in the Luzon Strait. The resultant meridional overturning has a net transport from north to south in the surface layer $(0-240 \mathrm{~m})$ and a return transport to north at the depth of about $500 \mathrm{~m}$ in winter and at about $200 \mathrm{~m}$ in summer. It shows the transport path of intermediate water in the SCS. Liu et al. [32] reported the whole depth SCS MOC based on the SODA reanalysis. The upper-layer MOC is similar to the result of Wang et al. [31], while the deep-layer MOC has a net transport of $0.8 \mathrm{~Sv}$ from south to north. The intruding Pacific Deep Water crosses the Luzon strait, moves 

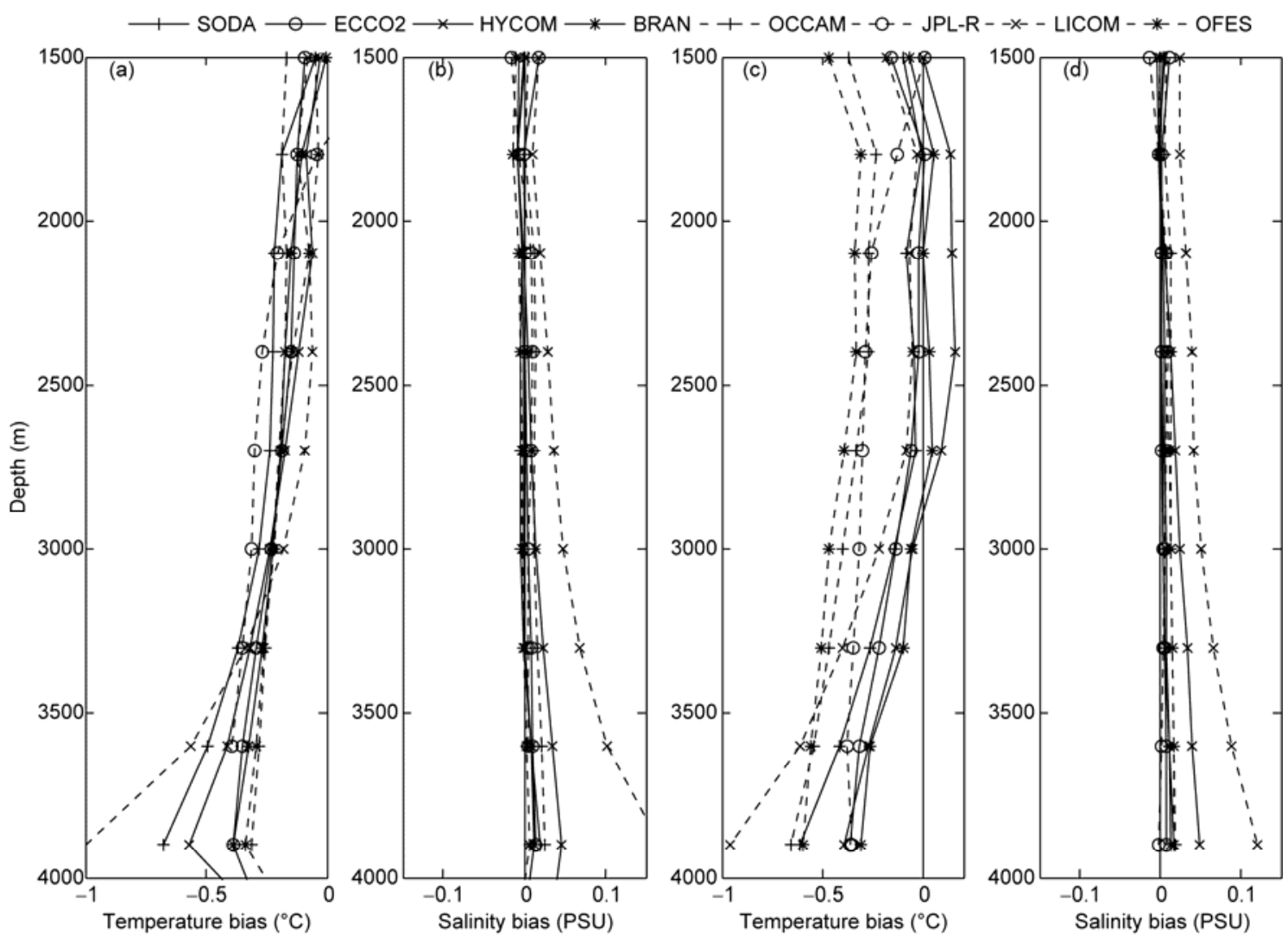

Figure 3 The mean profiles of temperature and salinity bias in the SCS ((a), (b)) and to the east side of Luzon Strait ((c), (d)).
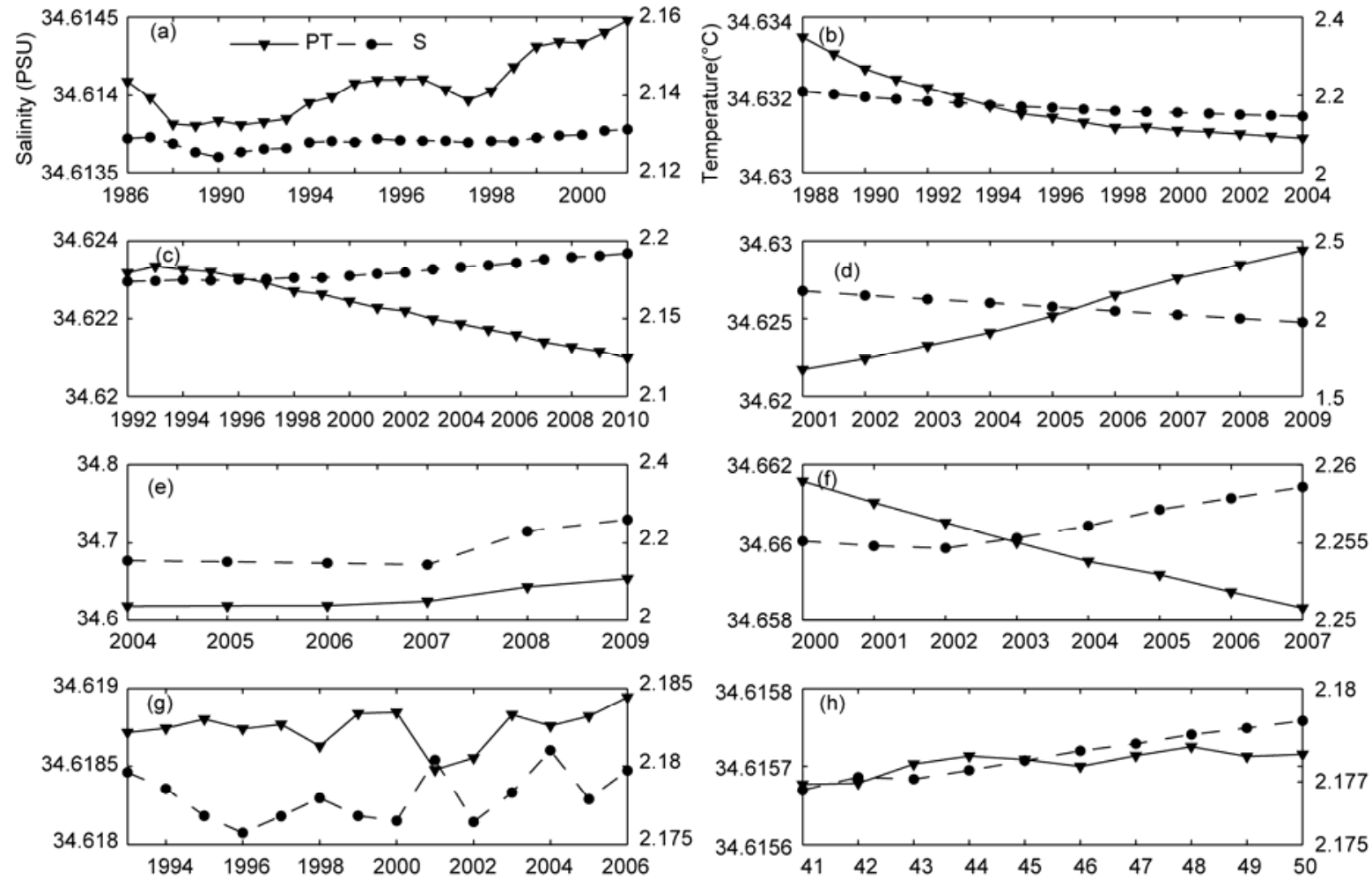

Figure 4 Interannual variation of basin-mean temperature (a) and salinity (b) at $2800 \mathrm{~m}$. (a) SODA; (b) OCCAM; (c) ECCO2; (d) JPL-R; (e) HYCOM; (f) LICOM; (g) BRAN; (h) OFES. 
Table 2 Luzon Strait mean transport and its standard deviation (inside parentheses) ${ }^{\text {a) }}$

\begin{tabular}{|c|c|c|c|c|c|c|c|c|c|}
\hline Dataset & SODA & $\mathrm{ECCO} 2$ & HYCOM & BRAN & OCCAM & JPL-R & LICOM & OFES & Mean \\
\hline Whole column & -1.70 & -4.86 & -5.22 & -5.50 & -4.06 & -6.02 & -5.86 & -3.42 & -4.92 \\
\hline (STD) & $(0.87)$ & $(2.23)$ & (1.96) & $(2.01)$ & (1.13) & $(3.89)$ & $(2.46)$ & $(1.48)$ & $(0.81)$ \\
\hline Upper layer & -1.69 & -4.56 & -5.55 & -7.14 & -3.78 & -5.63 & -5.66 & -3.45 & -5.33 \\
\hline$(0-500 \mathrm{~m})$ & $(1.19)$ & $(1.71)$ & $(2.33)$ & $(1.18)$ & (1.48) & $(3.44)$ & (1.93) & $(1.68)$ & $(1.37)$ \\
\hline Mid-depth layer & 0.70 & 0.01 & 1.03 & 1.91 & 0.39 & -0.60 & 0.05 & 0.06 & 0.77 \\
\hline$(500-1500 \mathrm{~m})$ & $(0.36)$ & $(0.46)$ & $(0.49)$ & $(0.62)$ & $(0.34)$ & $(1.13)$ & $(0.70)$ & $(0.38)$ & $(0.79)$ \\
\hline Deep layer & -0.71 & -0.31 & -0.70 & -0.26 & -0.67 & 0.21 & -0.25 & -0.03 & -0.36 \\
\hline
\end{tabular}

a) Positive (negative) transport value means there is net transport out of (into) the SCS (units: $1 \mathrm{~Sv}=106 \mathrm{~m}^{3} / \mathrm{s}$ ).

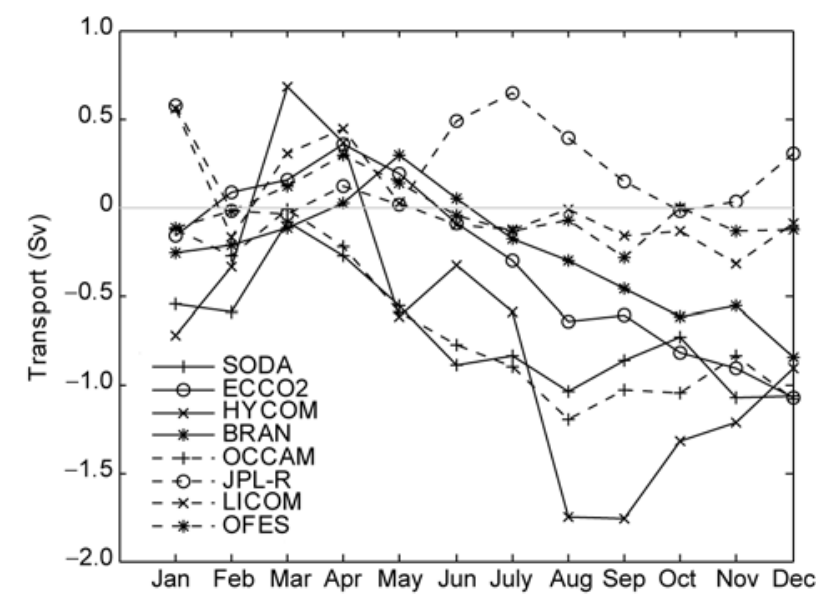

Figure 5 Seasonal variation of the deep-layer Luzon Strait transport .

southward, and then upwells in the southern SCS because the topography slopes upward. Finally, it splits into two branches: one flows out of the SCS through the Karimata Strait, and the other becomes part of the SCS intermediate water. As shown in Figure 6, there are an anti-cyclonic vertical cell between $8^{\circ}$ and $18^{\circ} \mathrm{N}$ and a cyclonic vertical cell between $20^{\circ}$ and $22^{\circ} \mathrm{N}$ above $1000 \mathrm{~m}$ in all simulations. However, there are many in consistencies between datasets below $1500 \mathrm{~m}$. Compare with the deep SCS MOC below $2400 \mathrm{~m}$, there is a weak anti-cyclonic vertical cell in these datasets. The discrepancy of the deep SCS MOC in these models may indicate, at least in part, different ventilation processes of the intruding Pacific Deep Water in the models.

\subsection{The horizontal streamfunction in deep SCS}

Based on GDEMv3, Wang et al. [15] argued that there is a basin-scale cyclonic circulation over the deep SCS. Choosing $2400 \mathrm{~m}$ as the level of no motion, the geotropic velocity is calculated from GDEMv3. Then, the horizontal streamfuction is obtained through integrating from the bottom to $2400 \mathrm{~m}$. For the model outputs, the streamfuction is directly calculated from the $u$ and $v$ fields from the bottom to 2400 $\mathrm{m}$. The results are shown in Figuire 7. There is a weak basin-scale cyclonic circulation in the model outputs except for a strong one in JPL-R. Compared with GDEMv3, the cyclonic gyre in the model is shifted westward. There are three or four eddies accompanying the large-scale cyclonic gyre in LICOM and BRAN. The deep vertically integrated streamfunction in HYCOM is closer to that in GDEMv3 as shown in Figure 7. Note that the net transport of deep-layer Luzon Strait in JPL-R is eastward, and that its deep-layer horizontal circulation is cyclonic. These features contradict the more commonly accepted Luzon Strait deep overflow forcing mechanism, which suggests there is a cyclonic circulation in the deep SCS if the deep-layer Luzon Strait transport is westward (into the SCS), or there is an anticyclonic circulation if the deep-layer Luzon Strait transport is eastward (out of the SCS). Because of many eddies in JPL-R, the nonlinear interaction of eddy and topography may trigger a large-scale cyclonic gyre in the deep SCS. This possible driving mechanism was reported by Holloway [33].

\section{Discussions}

\subsection{Difference in the two observational datasets}

The initial T/S fields used in these models are derived from WOA01 except for HYCOM. The T/S at $3000 \mathrm{~m}$ between WOA01 and GDEMv3 are shown in Figure 8. The water in the deep Phillipine Sea in both WOA01 and GDEMv3 is colder and saltier than that in the deep SCS. The salinity of eastern basin in the deep SCS is fresher than that of western basin, while the pattern of temperature is cold-warm-cold from the northeast to the southwest. But large differences exist between these two datasets. There is saline water mass along the northern boundary in GDEMv3 but not in WOA01. The fresh and cold water mass to the west of Luzon Island in GDEMv3 spreads westward more widely than that in WOA01. From $12^{\circ}$ to $15^{\circ} \mathrm{N}$, there is cold and saline water mass in WOA01, but not in GDEMv3.

Actually, the data of GDEMv3 are smoother than those of WOA01. The diagnostic current based on the method of Wang et al. [15] from GDEMv3 is stronger than that from WOA01 (Figure 9), althouth the large-scale flow field is cyclonic in both datasets. Compared to the current at 3000 $\mathrm{m}$ in GDEMv3, the strong cyclonic gyre in WOA01 is located in the southwestern SCS basin, with no obvious cyclonic gyre in the northern basin. So, for future simulation, GDEMv3 is recommended as the $\mathrm{T} / \mathrm{S}$ initial field in the ocean model. 


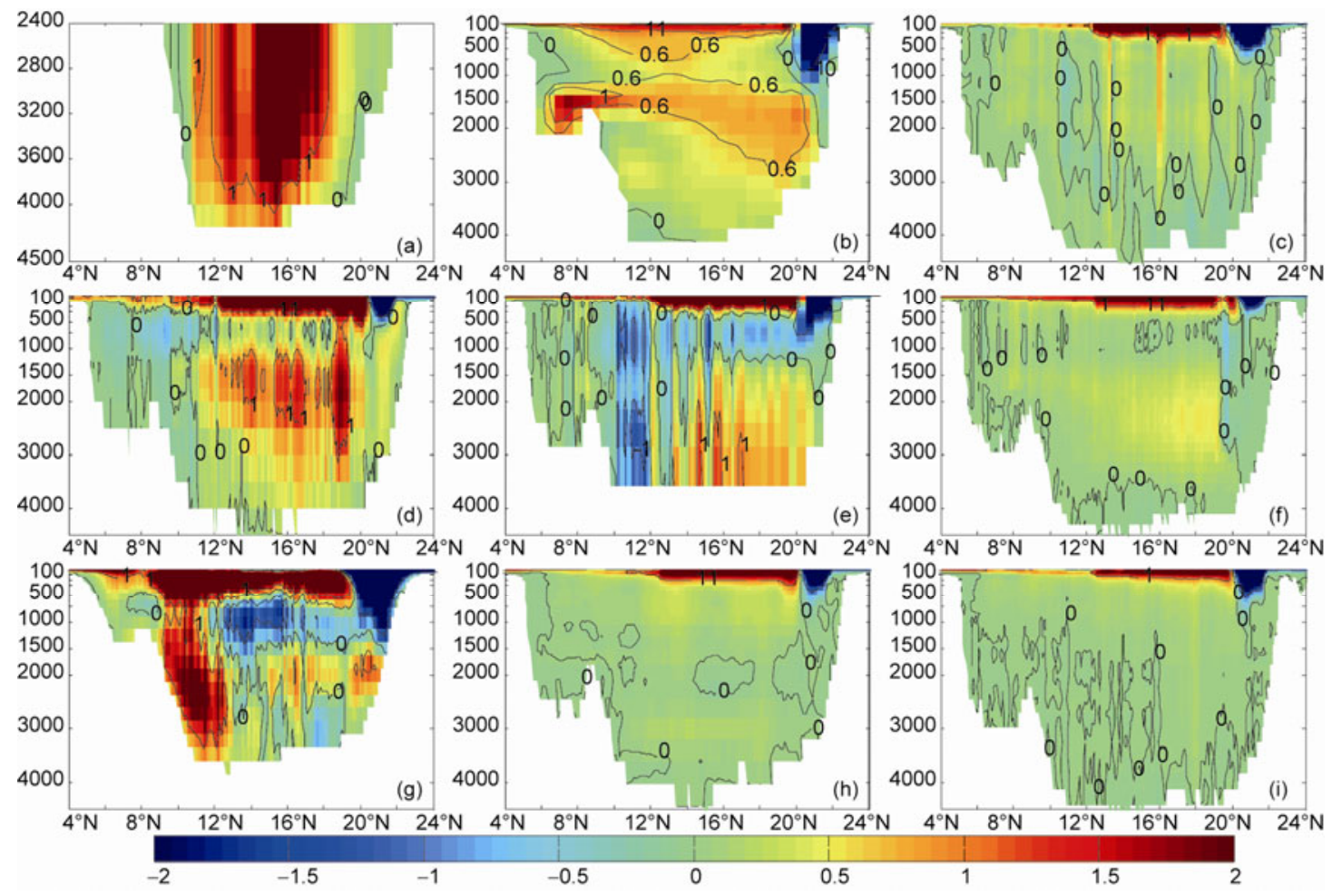

Figure 6 Mean meridional overturning streamfunction (units: Sv, contours and shadings). The vertical axis denotes the depth (units: m). (a) GDEMv3; (b) SODA; (c) ECCO2; (d) HYCOM; (e) BRAN; (f) OCCAM; (g) JPL-R; (h) LICOM; (i) OFES.
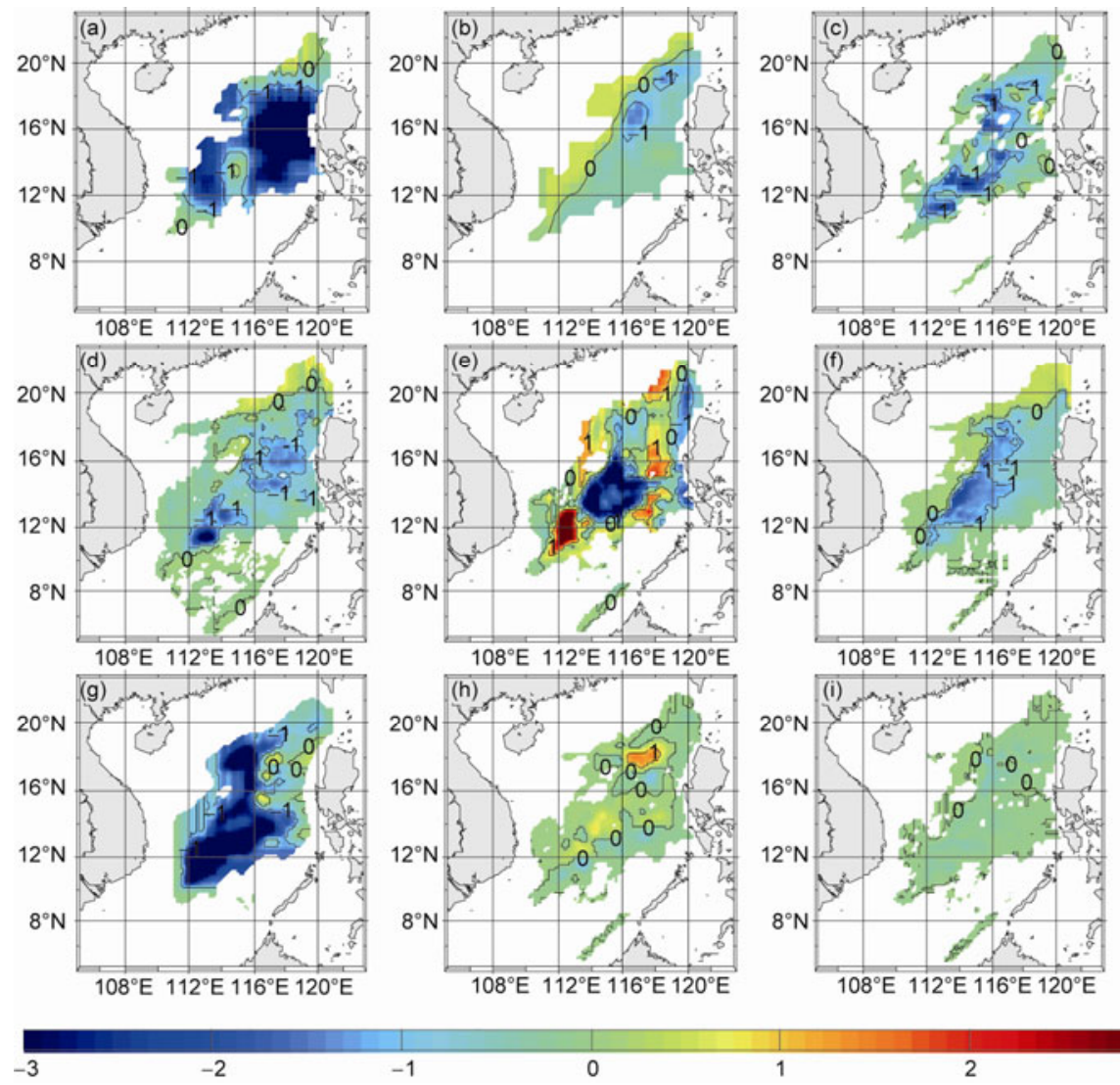

$-2$

0

Figure 7 Vertically integrated streamfunction (units: Sv, contours and shadings). (a) GDEMv3; (b) SODA; (c) ECCO2; (d) HYCOM; (e) BRAN; (f) OCCAM; (g) J PL-R; (h) LICOM; (i) OFES. 

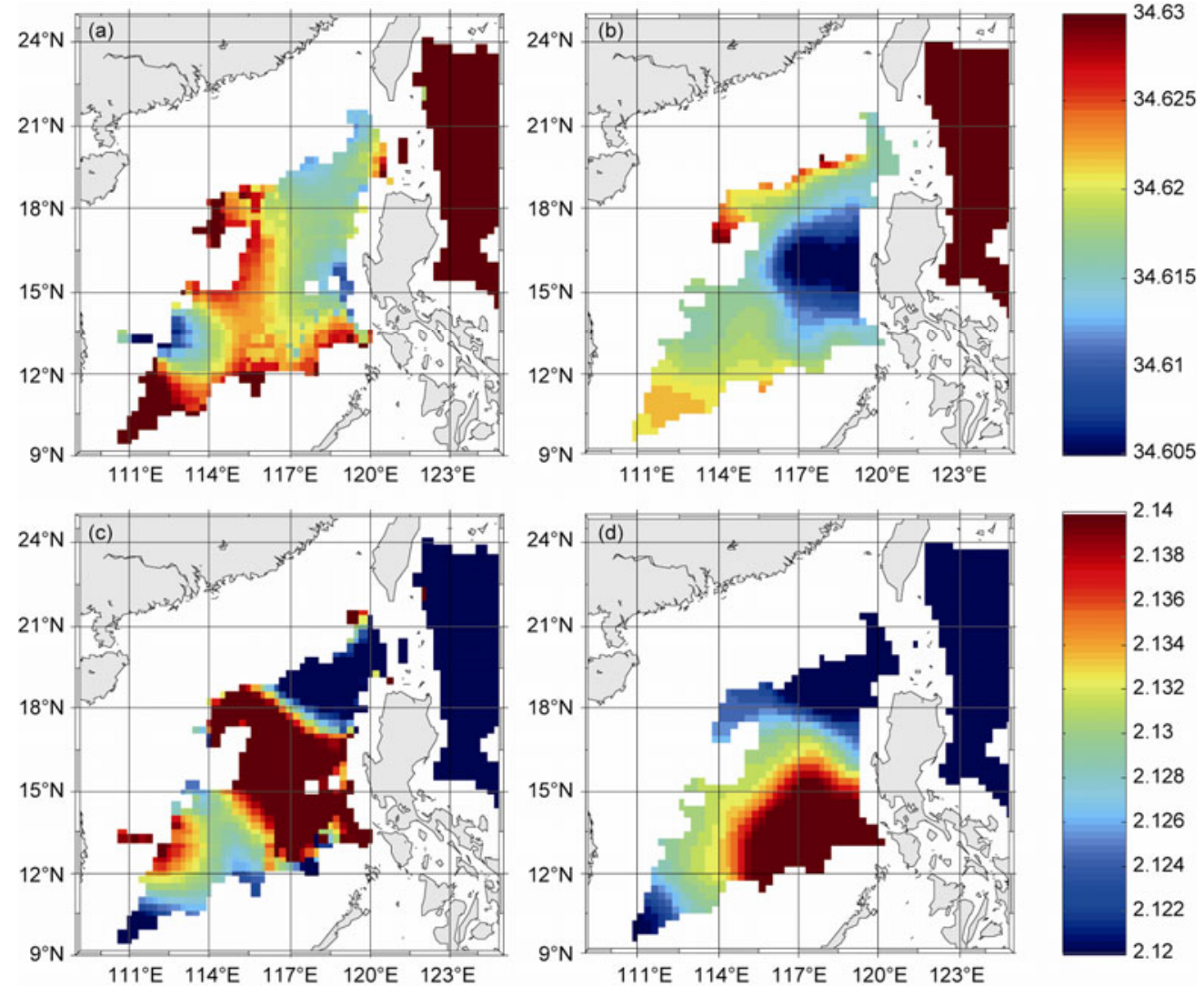

Figure 8 Salinity and potential temperature at $3000 \mathrm{~m}$ in WOA01 ((a), (c)) and GDEMv3 ((b), (d)).
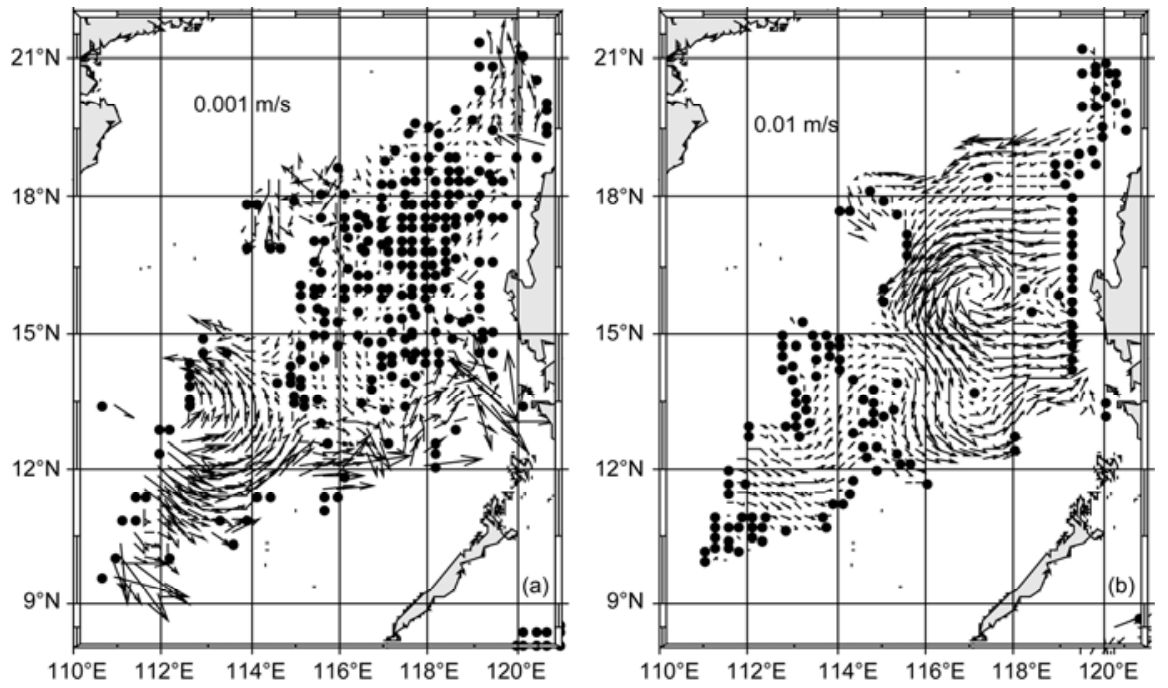

Figure 9 Currents at 3000 m, diagnosed from WOA01 (a) and GDEMv3 (b).

\subsection{The sensitivity of SCS deep-layer circulation to topography}

Since the forcing fields are very different in these models, the relationship between model topography and deep-layer SCS circulation is discussed here. The depth-averaged linear shallow-water momentum equations are

$$
\frac{\partial}{\partial t} \vec{u}+\vec{k} \times f \vec{u}=-g \nabla \eta+\frac{\vec{\tau}}{\rho \mathrm{H}}-\frac{\mathrm{R} \vec{u}}{\mathrm{H}},
$$

where $\vec{u}$ is the horizontal velocity vector, $g$ is the gravitational acceleration, $\eta$ is the sea surface displacement, $\rho$ is the density, $\vec{\tau}$ is the wind stress, $f$ is the Coriolis parameter, and $H$ is depth. A Rayleigh drag is also included. In the 
barotropic context, this represents Ekman drag so that $R=(v f / 2)^{0.5}$ (with an effective kinematic viscosity $\left.v\right)$. With stratification, other processes could dominate over bottom drag (e.g. lateral eddy diffusion), and so one may wish to incorporate lateral diffusion directly. However, diffusion term makes the problem more complex analytically. A linear drag, moreover, will be fairly adequate when comparing with most of the observations.

Taking the curl of eq. (4) yields the vorticity equation:

$$
\frac{\partial}{\partial t} \nabla \times \vec{u}+J\left(\psi, \frac{f}{H}\right)=v \times \frac{\vec{\tau}}{\rho H}-\nabla \times \frac{\mathrm{R} \overrightarrow{\mathrm{u}}}{H},
$$

after invoking the depth-integrated continuity equation and the rigid-lid approximation. $\psi$ is the transport streamfunction and $J$ is the Jacobian operator.

Nondimensionalize eq. (7) and we have

$$
\varepsilon \frac{\partial}{\partial t} \nabla \times \vec{u}+J\left(\psi, \frac{f}{H}\right)=\varepsilon \times \frac{\vec{\tau}}{H}-\varepsilon \nabla \times \frac{\overrightarrow{\mathrm{u}}}{H},
$$

where $\varepsilon=\frac{R}{f_{0} H_{0}}$. For the deep-layer SCS, $R=0.0008$, $f_{0} \approx 10^{-5}, H_{0} \approx 1000 \mathrm{~m}$, then $\varepsilon \sim 10^{-11}$. The terms related with $\varepsilon$ can be neglected, which yields

$$
J\left(\psi_{0}, \frac{f}{H}\right)=0 .
$$

Eq. (7) means the current is parallel to the contours of topography. The PV field $\frac{f}{H}$ mostly depends on $H$ in the deep-layer SCS. Differentiating eq. (7) yields

$$
|\bar{u}| \propto \frac{|\nabla H|}{H^{2}} .
$$

From eq. (8), we can see that the current in deep ocean depends on the water depth and the slope of bathymetry.

The situation is altered somewhat by stratification. Taking the curl of the depth-averaged momentum equations, including a baroclinic density field, we have

$$
\frac{\partial}{\partial t} \nabla \times \bar{u}+J\left(\psi, \frac{f}{H}\right)=J\left(\chi, \frac{1}{H}\right)+\nabla \times \frac{\vec{\tau}}{\rho H}-\nabla \times \frac{\mathrm{R} \overrightarrow{\mathrm{u}}}{H} .
$$

$$
J\left(\chi, \frac{1}{h}\right) \text { is joint effect of baroclinicity and relief }
$$

(JEBAR) term where $\chi=\frac{1}{\rho_{0}} \int_{-H}^{0} g \rho z \mathrm{~d} z$. Because JEBAR involves the Jacobian with $1 / H$, it vanishes when integrated around a depth contour. Integrating (9) yields

$$
\begin{aligned}
& \iint \frac{\partial}{\partial t} \nabla \times \vec{u} \mathrm{~d} x \mathrm{~d} y+\iint J\left(\psi, \frac{f}{H}\right) \mathrm{d} x \mathrm{~d} y \\
& \quad=\iint v \times \frac{\vec{\tau}}{\rho H} \mathrm{~d} x \mathrm{~d} y-\iint \nabla \times \frac{\mathrm{R} \overrightarrow{\mathrm{u}}}{H} \mathrm{~d} x \mathrm{~d} y .
\end{aligned}
$$

Using the same procedures as in the barotropic case, it also yields eq. (8). From the above derivation, it is found that in either the barotropic case or the baroclinic case, the circulation in the deep-layer SCS has a close relationship with topography.

To validate eq. (8), Exp topo_h and Exp topo_l are used to test the sensitivity of the deep-layer SCS circulation to topography variation using the Princeton Ocean Model [34]. Figure 10(a) shows the high-resolution topography used in Exp topo_h, while Figure 10(b) shows the low resolution in Exp topo_1 (after 9-point smoothing on the topography data used in Exp topo_h). Except for the topography, the other conditions are the same for these two experiments. The model with 3-D calculation with $\mathrm{T}$ and $\mathrm{S}$ held fixed is initialized by $\mathrm{T} / \mathrm{S}$ of GDEMv3 and driven by climatological QuikSCAT wind stress and thermohaline forcing derived from the NCEP/NCAR reanalysis. The open boundary is specified using SODA reanalysis. The Luzon Strait is open till $2500 \mathrm{~m}$ and the gyre pattern is similar from 2000 to $2500 \mathrm{~m}$. Figure 10(c) and (d) respectively shows the currents at $2000 \mathrm{~m}$ in Exps topo_h and topo_l. It is found that the deep-layer SCS gyre is cyclonic and trapped near the boundaries. The difference between the two experiments is that the velocity in Exp topo_h is larger than that in Exp topo_l.

From eq. (8), we can see that when $\frac{|\nabla H|}{H^{2}}$ is larger, the velocity $|\bar{u}|$ is larger. Figure 11(a) and (c) shows $\frac{|\nabla H|}{H^{2}}$ and $|\bar{u}|$ in Exp topo_h, respectively; Figure 11(b) and (d) shows the results of Exp topo_l. From Exp topo_h to Exp topo_1, $\frac{|\nabla H|}{H^{2}}$ is greatly reduced, so the velocity $|\bar{u}|$ becomes weak in Exp Topo_l. Based on eq. (8) and simulation results, it is inferred that the deep-layer SCS circulation is sensitive to the resolution of topography. The difference in topography can bring changes in the deep-layer SCS gyre.

\subsection{The effects of vertical mixing on MOC}

Either PP scheme [35] or KPP scheme [36] is implemented in most ocean models, which originally depicts mixing processes by means of eddy mixing that is Richardson-number dependent in the region below the core of the Equatorial Undercurrent where vertical temperature gradient is small but the shear is large. These mixing schemes actually represent background mixing below the thermocline over rough topographies in the deep ocean. But the deep circulation is mainly driven by vertical mixing caused by internal waves generated by tidal currents interacting with rough bottom topography, as Munk and Wunsch [37] argued that tidal mixing is an important forcing for the deep ocean circulation. In recent years, intense localized mixing with diapycnal diffusivity higher than $10^{-5} \mathrm{~m}^{2} \mathrm{~s}^{-1}$ has been found 

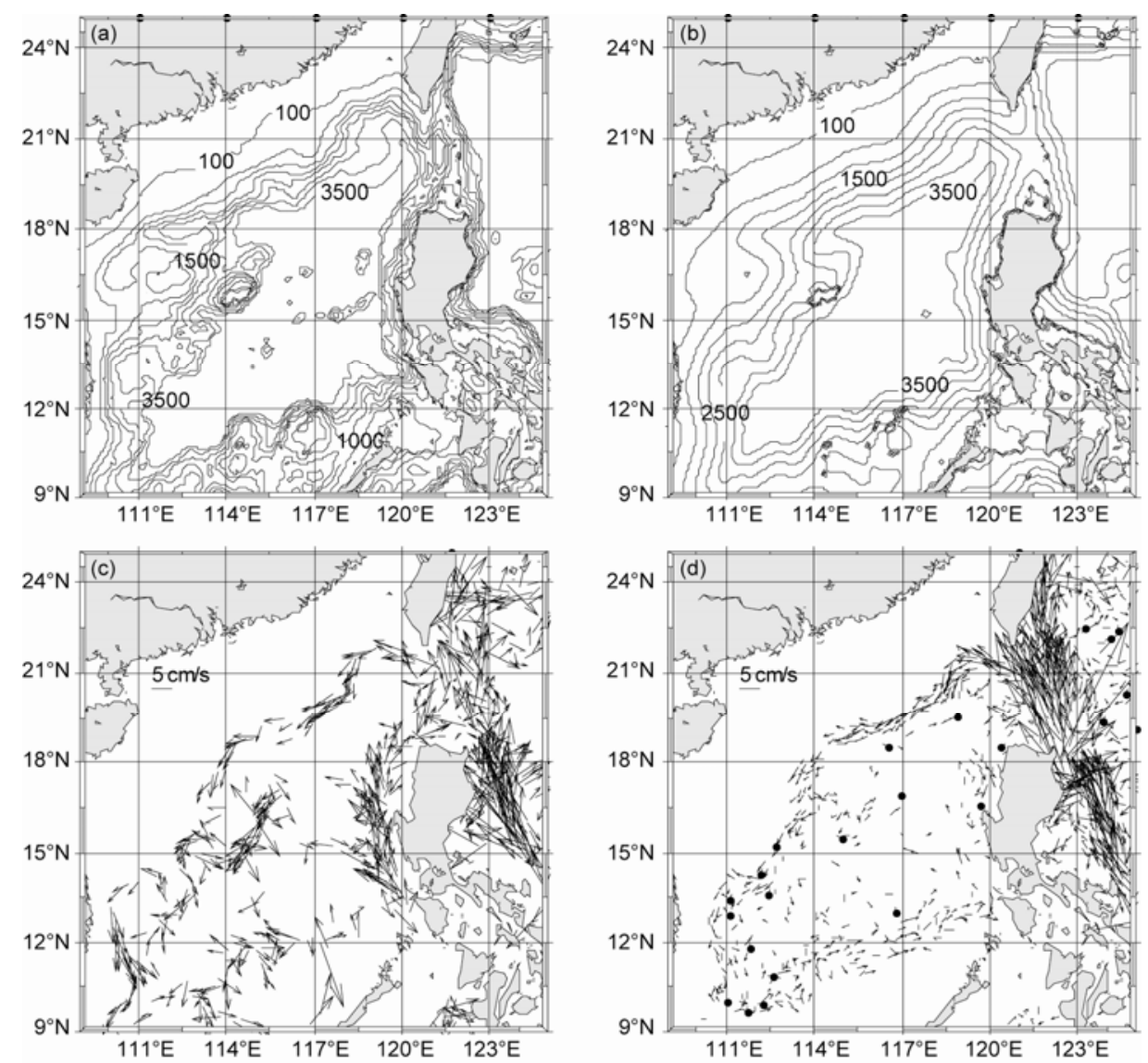

Figure 10 Bathemetry and currents at the depth of 2000 m. (a) Bathemetry in Experiment topo_h; (b) bathemetry in Experiment topo_l; (c) currents in Experiment topo_h; (d) currents in Experiment topo_1.

to occur over rough topography, such as seamounts, ridges, canyons, and hydraulically controlled passages between basins [38-41]. In these areas, turbulent mixing has been inferred to be 100-1000 times larger than that of the ocean interior. Laurent et al. [42] estimated the tidal mixing magnitude around steep bottom is nearly $\mathrm{O}\left(10^{-3} \mathrm{~m}^{2} \mathrm{~s}^{-1}\right)$. Tian et al. [43] showed that diapycnal diffusivity in the SCS and the Luzon Strait is elevated by two orders of magnitude over that of the smooth bathymetry in the North Pacific, which has a typical background value of an open ocean. In addition, Egbert and Ray [44] estimated that the $\mathrm{M}_{2}$ tide dissipation is $40 \mathrm{GW}$, which is the same order as $10 \mathrm{GW}$ from the results of Tian et al. [43].

Simmons et al. [45] incorporated the tidal mixing parameterization [46] into MOM3. Their results showed that the scheme resulted in a substantial reduction of temperature/salinity biases. This suggests that spatially varying bottom-intensified mixing is an essential component of the balance required for the maintenance of ocean's abyssal stratification. Saenko and Merryfield [47] found that allowing for enhanced diapycnal mixing above rough topography led to increased bottom-water circulation and deep stratification and a potential vorticity distribution in the North $\mathrm{Pa}$ cific that is much more realistic. And the enhanced diapycnal mixing above rough topography results in a significant intensification and deepening of the Antarctic Circumpolar Current, as well as in stronger bottom-water formation around the Antarctica. Jayne [48] showed the tidal mixing parameterization has a noticeable impact on the MOC. These modeling results confirm the scaling law $\varphi \propto K_{\rho}^{2 / 3}$ where $\varphi$ is MOC and $K_{\rho}$ is mixing coefficient derived by Nilsson et al. [49].

What is the mixing value in each of these models? This can be answered by choosing $120.5^{\circ} \mathrm{E}$ section in the Luzon Strait, which can then be compared to the observational study of Tian et al. [43]. We calculate the mixing value based on the PP Scheme. The scheme is as follows:

When $R i<0, K_{\rho}=K_{m}$; but when $R i>0, K_{\rho}$ is defined as

$$
K_{\rho}=\frac{K_{m}}{(1+5 R i)^{3}}+K_{0}
$$

where $K_{m}=5.0 \times 10^{-3} \mathrm{~m}^{2} \mathrm{~s}^{-1}, \quad K_{0}=10^{-5} \mathrm{~m}^{2} \mathrm{~s}^{-1}, \quad$ and $R i=\frac{\frac{g}{\rho_{0}} \frac{\partial \rho_{\theta}}{\partial z}}{\left[\left(\frac{\partial u}{\partial z}\right)^{2}+\left(\frac{\partial v}{\partial z}\right)^{2}\right]}$. 

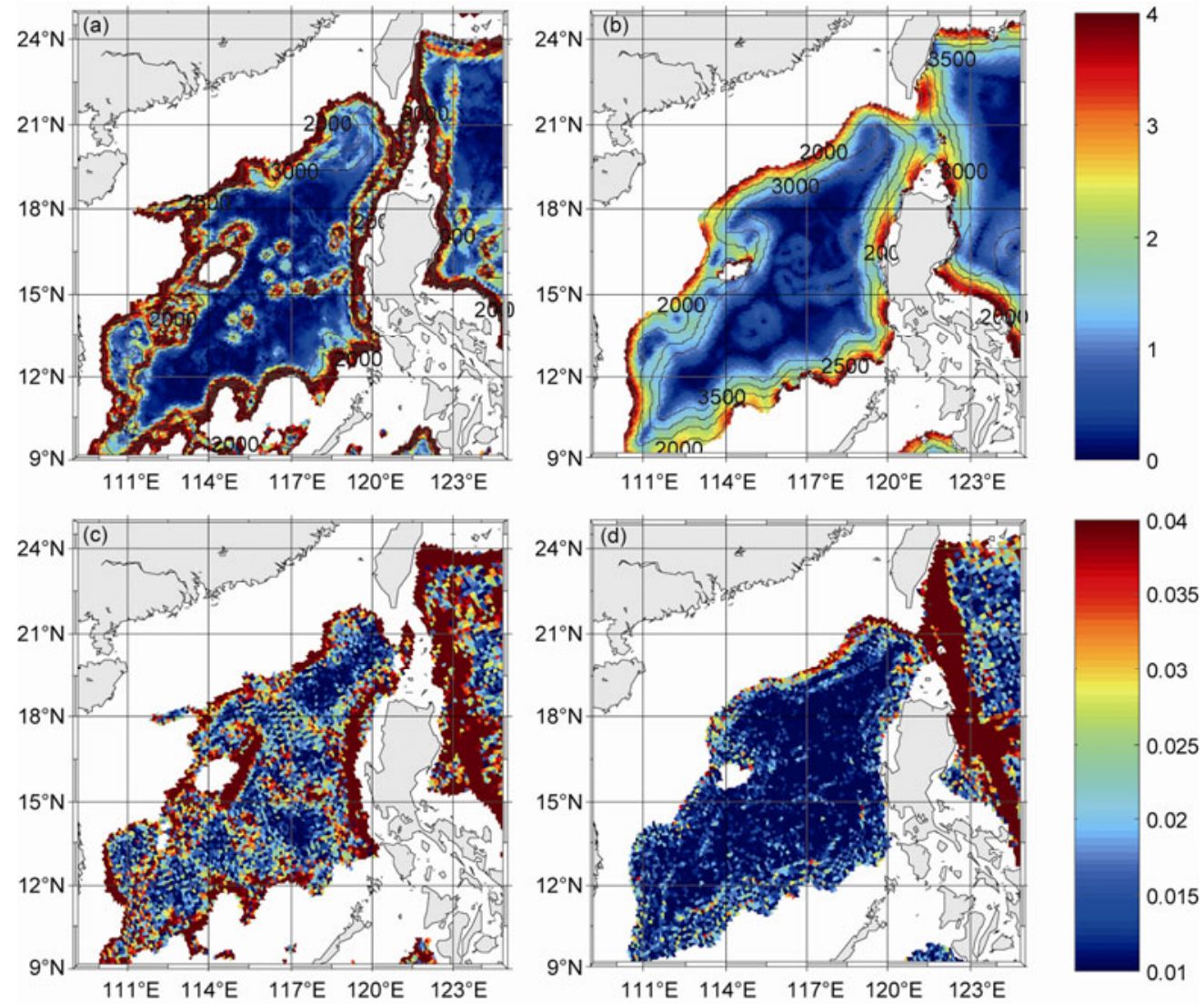

Figure $11 \frac{|\nabla H|}{H^{2}}$ ( unit: $10^{-9} \mathrm{~m}^{-2}$ ) and velocity at the depth of $2000 \mathrm{~m}$. (a) $\frac{|\nabla H|}{H^{2}}$ in Experiment topo_h; (b) $\frac{|\nabla H|}{H^{2}}$ in Experiment topo_1; (c) velocity in Experiment topo_h; (d) velocity in Experiment topo_1.

The mixing value in these model outputs is $\mathrm{O}\left(10^{-5}\right)$, which is smaller than the estimate of Tian et al. [43] by two orders. This is consistent with Figure 6, which indicates the overturning is weak in the models because of weak mixing according to the scaling law $\varphi \propto K_{\rho}^{2 / 3}$. Therefore, we suggest the tidal mixing scheme be implemented in the ocean models to improve the simulation of deep-layer SCS MOC.

\section{Conclusions}

This study provides a preliminary analysis of eight quasi-global high-resolution ocean model outputs of SCS deep-layer circulation. Water mass analysis reveals that deep temperature in the models is colder than that of WOA01. The Luzon Strait transport below $1500 \mathrm{~m}$ is 0.36 $\mathrm{Sv}$ on average, less than the estimate from observations. Four assimilated outputs and one unassimilated (OCCAM) display that the Luzon Strait deep overflow reaches a minimum in spring and a maximum in winter. The vertically integrated streamfunction below $2400 \mathrm{~m}$ shows a deep cyclonic circulation in the SCS on a large scale, but the pattern is very different compared to that from GDEMv3. The me- ridional overturning streamfunction above $1000 \mathrm{~m}$ is similar in all the models, but the spatial distribution and intensity below $1500 \mathrm{~m}$ are quite different among the models. Moreover, the MOC below $2400 \mathrm{~m}$ is weaker in the models, compared with that of GDEMv3, which indicates deep water renewal is weak in these models. This paper also discusses the impacts of $\mathrm{T} / \mathrm{S}$ initial value,topography, mixing scheme on the SCS deep-layer circulation.

Since the mixing is very strong in deep-layer SCS, it is necessary to modify the mixing scheme in the ocean model to be consistent with observations. The tidal mixing scheme is a suitable one for improving simulation. Moreover, the SCS bottom topography is complex, and it is already known that SCS deep-layer circulation is very sensitive to the accuracy of topography. So, we suggest that smoothing model topography be avoided. Finally, the model spin-up time should be at least 30 years in using the strong tidal mixing scheme according to $\mathrm{Qu}$ et al. [10].

This work was supported by the National Basic Research Program of China (41276024 and 41276024), the Knowledge Innovation Engineering Frontier Project of Sanya Institute of Deep Sea Science and Engineering (SIDSSE-201205), and Sanya and Chinese Academy of Sciences Cooperation Project (2012YD01). 
1 Stommel H, Arons A B. On the abyssal circulation of the world ocean - I. Stationary flow patterns on a sphere. Deep-Sea Res, 1960, 6: $140-154$

2 Stommel H, Arons A B. On the abyssal circulation of the World Ocean-II. An idealized model of the circulation pattern and amplitude in oceanic basins. Deep-Sea Res, 1960, 6: 217-233

3 Broecker W S, Patzert W C, Toggweiler J R, et al. Hydrography, chemistry, and radioisotopes in the southeast Asian basins. J Geophys Res, 1986, 91: 345-354

4 Nitani H. Beginning of the Kuroshio, in Kuroshio: Physical Aspects of the Japan Current. Seattle: University of Washington Press, 1972. 129-163

5 Wyrtki K. Physical oceanography of the southeast Asian waters. Naga Rep 2, 195 pp, Scripps Inst of Oceanogr, La Jolla, Calif La Jolla, California: University of California, Scripps Institution of Oceanography, 1961. 93-107

6 Wang J. Observation of abyssal flows in the Northern South China Sea. Acta Oceanogr Taiwan, 1986, 16: 36-45

7 Liu C T, Liu R J. The deep current in the Bashi Channel. Acta Oceanogr Taiwan, 1988, 20: 107-116

8 Qu T, Mitsudera H, Yamagata T. Intrusion of the North Pacific waters into the South China Sea. J Geophys Res, 2000, 105: 6415-6424

9 Qu T. Evidence of water exchange between the South China Sea and the Pacific through the Luzon Strait. Acta Oceanol Sin, 2002, 21: 175-185

10 Qu T, Girton J B, Whitehead J A. Deep water overflow through Luzon Stait. J Geophys Res, 2006, 111: C01002

11 Li L, Qu T. Thermohaline circulation in the deep South China Sea basin inferred from oxygen distributions. J Geophys Res-Oceans, 2006, 111: C05017

12 Tian J, Yang Q, Liang X, et al. Observation of Luzon Strait transport. Geophys Res Lett, 2006, 33: L19607

13 Chang Y T, Hsu W L, Tai J H, et al. Cold deep water in the South China Sea. J Oceanogr, 2010, 66: 183-190

14 Yang Q, Tian J, Zhao W. Observation of Luzon Strait transport in summer 2007. Deep Sea Res, Part I, 2010, 57: 670-676

15 Wang G, Xie S P, Qu T, et al. Deep South China Sea circulation. Geophys Res Lett, 2011, 38: L05601

16 Fang G, Susanto D, Soesilo I, et al. A note on the South China Sea shallow interocean circulation. Adv Atmos Sci, 2005, 22: 946-954

17 Sun X, Li X, Geng J, et al. Deep water bottom current deposition in the northern. Sci China Ser D-Earth Sci, 2007, 50: 1060-1066

18 Luedmann T, Wong H K, Berglar K. Upward flow of North Pacific Deep Water in the northern South China Sea as deduced from the occurrence of drift sediments. Geophys Res Lett, 2005, 32: L05614

19 Tian J W, Qu T D. Advances in research on the deep South China Sea circulation. Chin Sci Bull, 2012, 57: 3115-3120

20 Chao S Y, Shaw P T, Wu S Y. Deep water ventilation in the South China Sea. Deep Sea Res Part I, 1996, 43: 445-466

21 Yuan D. A numerical study of the South China Sea deep circulation and its relation to the Luzon Strait transport. Acta Oceanol Sin, 2002, 21: 187-202

22 Masumoto Y, Sasaki H, Kagimoto T, et al. A fifty-year eddyresolving simulation of the world ocean-Preliminary outcomes of OFES (OGCM for the Earth Simulator). J Earth Simulator, 2004, 1: 35-56

23 Thoppil P G, Richman J G, Hogan P J. Energetics of a global oceancirculation model compared to observations. Geophys Res Lett, 2011, 38: L15607

24 Xiu P, Chai F, Shi L, et al. A census of eddy activities in the South China Sea during 1993-2007. J Geophys Res, 2010, 115: C03012

25 Schiller A, Oke P R, Brassington G B, et al. Eddy-resolving ocean circulation in the Asian-Australian region inferred from an ocean re- analysis effort. Prog Oceanogr, 2008, 76: 334-365

26 Yu Y Q, Liu H L, Lin P F. A quasi-global $1 / 10^{\circ}$ eddy-resolving ocean general circulation model and its preliminary results. Chin Sci Bull, 2012, 57: 3908-3916

27 Boyer T, Levitus S, Garcia H, et al. Objective analyses of annual, seasonal, and monthly temperature and salinity for the world ocean on a $0.25^{\circ}$ grid. Int J Climatol, 2005, 25: 931-945

28 Carnes M R.Description and evaluation of GDEM-V3.0.2009, Washington D.C: NRL Rep, 2009: NRL/MR/7330-09-9165

29 Canuto V M, Howard A, Cheng Y, et al. Ocean turbulence. Part I: One-point closure model-momentum and heat vertical diffusivities. J Phys Oceanogr, 2001,31: 1413-1426

30 Canuto V M, Howard A, Cheng Y, et al. Ocean turbulence. Part II: Vertical diffusivities of momentum, heat, salt, mass, and passive scalars. J Phys Oceanogr, 2002, 32: 240-264

31 Wang D, Liu X, Wang W. et al. Simulation of meridional overturning in the upper layer of the South China Sea with an idealized bottom topography. Chin Sci Bull, 2004, 49: 740-747

32 Liu C J, Du Y, Zhang Q R, et al. Seasonal variation of subsurface and intermediate water masses in the South China Sea. Oceanol Limnol Sin, 2008, 39: 55-64

33 Holloway G. Representing topographic stress for large scale ocean models. J Phys Oceanogr, 1992, 22: 1033-1046

34 Alan F B, George L M. A description of a three-dimensional coastal ocean circulation model. Amer Geophys Union, 1987, 1-16

35 Pacanowski R C, Philander S G H. Parameterization of vertical mixing in numerical models of tropical oceans. J Phys Oceanogr, 1981, 11: 1443-1451

36 Large W G, McWilliams J C, Doney S C. Oceanic vertical mixing: A review and a model with a nonlocal boundary layer parameterization. Rev Geophys, 1994, 32: 363-403

37 Munk W, Wunsch C. Abyssal recipes II: Energetics of tidal and wind mixing. Deep Sea Res, 1998, 45: 1977-2010

38 Heywood K J, Garabato A C N, Stevens D P. High mixing rates in the abyssal Southern Ocean. Nature, 2002, 415: 1011-1014

39 Polzin K L, Toole J M, Ledwell J R, et al. Spatial variability of turbulent mixing in the abyssal ocean. Science, 1997, 276: 93-96

40 Ledwell J R, Watson A J, Law C S. Evidence for slow mixing across the pycnocline from an open-ocean tracerrelease experiment. Nature, 1993, 364: 701-703

41 Morris M Y, Hall M M, Laurent L C St, et al. Abyssal mixing in the Brazil Basin. J Phys Oceanogr, 2001, 31: 3331-3348

42 Laurent L C St, Simmons H L, Jayne S R. Estimates of tidally driven enhanced mixing in the deep ocean. Geophys Res Lett, 2002, 29: 2106

43 Tian J, Yang Q, Zhao W. Enhanced diapycnal mixing in the South China Sea. J Phys Oceanogr, 2009, 39: 3191-3203

44 Egbert G D, Ray R D. Significant dissipation of tidal energy in the deep ocean inferred from satellite altimeter data. Nature, 2000, 405: 775-778

45 Simmons H L, Jayne S R, Laurent L C St, et al. Tidally driven mixing in a numerical model of the ocean general circulation. Ocean Model, 2004, 6: 245-263

46 Jayne S R, Laurent L C St. Parameterizing tidal dissipation over rough topography. Geophys Res Lett, 2001, 28: 811-814

47 Saenko O A, Merryfield W J. On the effect of topographically enhanced mixing on the global ocean circulation. J Phys Oceanogr, 2005, 35: 826-834

48 Jayne S R. The impact of abyssal mixing parameterizations in an ocean general circulation model. J Phys Oceanogr, 2009, 39: 17561775

49 Nilsson J, Göran B, Gösta W. The Thermohaline circulation and vertical mixing: Does weaker density stratification give stronger overturning? J Phys Oceanogr, 2003, 33: 2781-2795

Open Access This article is distributed under the terms of the Creative Commons Attribution License which permits any use, distribution, and reproduction in any medium, provided the original author(s) and source are credited. 